\title{
Type I Interferon Response in Calves Experimentally Infected with Bovine Viral Diarrhea Virus Type 1b and Mannheimia Haemolytica
}

\author{
Chase $\mathrm{JL}^{1}$, Wilson $\mathrm{BK}^{2}$, Hernandez Gifford $\mathrm{JA}^{3}$ and Gifford CA ${ }^{4 *}$ \\ ${ }^{1}$ Texas A\&M Agri Life Extension Service, Texas A\&M University, USA \\ ${ }^{2}$ Department of Animal Science, Oklahoma State University, USA \\ ${ }^{3}$ Department of Animal and Range Sciences, New Mexico State University, USA \\ ${ }^{4}$ Department of Extension Animal Sciences and Natural Resources, New Mexico State University, USA
}

*Corresponding author: Gifford CA, Department of Extension Animal Sciences and Natural Resources, New Mexico State University, Las Cruces, New Mexico 88003, USA.

Received Date: November 23, 2019

Published Date: December 03, 2019

\begin{abstract}
Bovine respiratory disease complex (BRDC) is a major health issue facing the feedlot industry and is the leading cause of morbidity and mortality in feedlot cattle. The genome of bovine viral diarrhea virus (BVDV), a common agent in BRDC, contains an amino terminus protease (Npro)that inhibits the type I interferon (IFN) response in vitro, however in vivo work indicates that thetype I IFN response is activated during BVDV infection. Dietary mineral status has been implicated in BRDC susceptibility in calves during shipping, but little is known regarding mineral supplementation and the IFN response. To determine if Cu deficiency or natural exposure to BVDV1b inhibits IFN signaling in vivo, Cu deficient ( $\mathrm{n}=6)$ or control $(\mathrm{n}=6)$ calves were infected with BVDV1b and Mannheimia haemolytica $(\mathrm{MH})$. Steady-state mRNA levels of MX1, ISG15, and RTP4 were determined in peripheral blood leukocytes prior to BVDV1b exposure (day -4), prior to MH challenge $(0 \mathrm{~h}$ ), and $12 \mathrm{~h}$ and $24 \mathrm{~h}$ after $\mathrm{MH}$ challenge. Changes in gene expression are relative to the average of day -4 values was quantified. No mineral effects were detected $(\mathrm{P}>0.10)$ so mineral deficient and supplemented groups were pooled. A significant time effect $(\mathrm{P}<0.05)$ for all interferon stimulated genes was detected. At $0 \mathrm{~h}$, ISG15 mRNA expression increased 44-fold and remained elevated over 60 -fold for $12 \mathrm{~h}$ and $24 \mathrm{~h}(\mathrm{P}<0.01)$. Likewise, RTP4 and MX1 increased at $12 \mathrm{~h}(\mathrm{P}<0.05)$ after BRD challenge. Data suggests that regardless of Cu status, the type I interferon pathway remains active after being challenged with BVDV1b and MH in vivo.
\end{abstract}

Keywords: BVDV; Bovine respiratory disease; Interferon; Mineral; Shipping fever

\section{Introduction}

Bovine respiratory disease complex (BRDC) is a major health and economic issue for feedlots in the United States. Bovine respiratory disease is responsible for roughly $\$ 800$ to 900 million dollars in lost revenue each year due to decreased feed efficiency, medicinal costs, and eat [1]. In 2011, an estimated $16.2 \%$ of all cattle in the United States were affected by respiratory disease, and $87.5 \%$ of those animals required treatment for the disease [2]. Treatment costs for BRDC have increased to $\$ 23.60$ per case which is double the cost observed in 1999 [2]. Bovine respiratory disease typically results from a co-infection of both viral and bacterial pathogens. Common viral agents include bovine viral diarrhea virus type 1 and 2 , parainfluenza type 3, and infectious bovine rhinotracheitis, bacterial agents include, Mannheimia haemolytica,
Pasturella multocida, and Haemophilus [3] In Oklahoma, bovine viral diarrhea virus (BVDV) and Mannheimia haemolytica are the two most common pathogens in BRDC cases [4] Viral infections activate the type I IFN pathway which in turn stimulates transcription of interferon stimulated genes [5]. Host pattern-recognition receptors (PRR) identify pathogen-associated molecular patterns (PAMPS) and stimulate innate immune activation and IFN production. Multiple PRR exist and are found in various cellular domains leading to a variety of pathways that can stimulate IFN production, but these pathways appear to converge at interferon regulatory factors(IRF) 3 and -7 [6]. Work utilizing in vitro models demonstrates that BVDV prevents binding of IRF-3 to DNA, thus inhibiting type I IFN production $[7,8]$ demonstrated that the NPro protein of BVDV 
blocks induction of IFN- $\beta$ by degrading IRF-3.Collectively, these results suggest that BVDV can disrupt the type I IFN pathway, thereby reducing the production of IFN, but these works were conducted strictly in vitro only. Conversely, studies which expose cattle in vivo to laboratory cultured BVDV appear to maintain type I IFN production Bovine respiratory disease complex is most often observed in cattle being shipped, and studies have suggested that mineral supplementation can alleviate rates of BRDC in shipped cattle. For example, calves fed organic trace mineral supplements were found to have higher concentrations of eosinophils, suggesting that they would be better able to cope with an inflammatory response [9]. Furthermore, addition of organic trace minerals to diets in feedlot cattle decreased the percentage of sick animals that needed second treatment of antibiotics for bovine respiratory disease [10]. This may indicate that while mineral status does not affect rate of morbidity, mineral deficiency potentially impairs the innate immune response. However, the effects of dietary minerals status on the type I IFN response have not been evaluated.

The objectives of the current study were to evaluate the type I IFN response in calves exposed to BVDV via exposure to a persistently infected (PI) calf and determine the effects of copper deficiency on type I IFN activation during viral exposure.

\section{Materials and Methods}

\section{Animals}

All procedures for this experiment were approved by the Oklahoma State University Institutional Animal Care and Use Committee (Animal Care and Use Protocol AG-12-5) Twelve bull calves were selected from an Angus based commercial cow herd. Calves were individually tagged, surgically castrated, and vaccinated for clostridial pathogens (Covexin 8; Merck Animal Health, Summit, NJ) at the ranch of origin 80 days prior to the start of the experiment. Blood samples from all calves were seronegative to BVDV at 80 days and 24 days prior to the start of the experiment. All calves were tested for persistent infection of BVDV by immunohistochemical analysis (Oklahoma Animal Disease and Diagnostic Laboratory,Stillwater, OK). Eleven days prior to the start of the experiment, calves were vaccinated for clostridial pathogens, infectious bovine keratoconjunctivitis (Autogenous Bacterin; Newport Laboratories, Worthington, MN) and viral pathogens, excluding BVDV, (Inforce; Zoetis,Florham Park, NJ). Calves were also treated for internal and external parasites (Ivermax Plus; Norbrook Laboratories, Lenexa, KS). Tilmicosin phosphate (300 mg per mL) was administered at the rate of $1.5 \mathrm{~mL}$ per $45.4 \mathrm{~kg}$ of BW (Micotil; Elanco Animal Health, Indianapolis, IN) and every calf was given a fly tag (Corathon; Bayer, Shawnee Mission, KS). Calves were then transported to the Animal Science Equine Center at Oklahoma State University for a 6-day weaning period.

After weaning, calves were transported to the Nutrition and Physiology Research Center (NPRC) at Oklahoma State University 5 days prior to the initiation of the experiment. Upon arrival calves were weighed, and, using body weight and initial antibody titers to
BVDV and MH, calves were allocated to experimental treatments of control (CONT) or copper deficient (CuDef). For 5 days calves were placed in individual metabolic stanchions with automatic waters and individual feed troughs to allow for adaptation. Calves were then randomly assigned to individual $3.05 \times 3.66 \mathrm{~m}$ slatted floor pens for 42 days (day -46 of experiment; day $0=\mathrm{MH}$ challenge) with access to automatic water bowls and individual feed bunks. During the 42day period prior to BRDC challenge, calves were fed diets that were not mineral supplemented or mineral supplemented (described below). The BVDV and MH challenge was conducted as described by [4] with minor modifications. Briefly, pre-BVDV peripheral blood leukocyte (PBL) samples were collected on day -4 (day $0=\mathrm{MH}$ challenge), calves were comingled in a common pasture for 4 days with a persistently infected (PI) animal [11]. On day 0 calves were gathered and placed in metabolic stanchions and pre-MH challenge PBL samples were taken. All calves received 10 $\mathrm{mL}$ of a solution containing $6 \times 10^{\wedge} 9 \mathrm{CFU}$ of MH serotype 1 that was reconstituted and grown prior to the challenge as described by Mosier et al. Mannheimia haemolytica was delivered via intratracheal bronchoalveolar by a licensed veterinarian (Dowling et al., 2002).

\section{Diet}

Prior to weaning, calves received no mineral supplementation. Upon arriving at the Horse Unit at OSU, calves were given ad libitum access to water, Bermuda grass hay, and a common receiving ration. After the calves were transported to the NPRC and placed in stanchions, Bermuda grass hay was removed, but the calves were still allowed ad libitum access to water and the common receiving ration. Calves received this ration ad libitum, for the duration of the experiment, along with ad libitum access to water. Calves were either mineral supplemented or non-mineral supplemented. The CONT calves received a ground corn top dress daily containing a common mineral supplement while the CuDef calves received a top dress of only ground corn daily. Dietary analysis showed that non-mineral supplemented calves were deficient in $\mathrm{Cu}$ only; ration ingredients provided adequate levels for all other minerals. During the 4 days of the BVDV challenge, calves were gathered at $0700 \mathrm{~h}$ each morning and sorted into their respective treatments, each receiving $11.3 \mathrm{~kg}$ of the common ration and their individual top dress.

\section{Clinical scores and rectal temperatures}

Rectal temperatures and clinical scores were documented for each calf at h 0 (at MH challenge), 2, 4, 6, 12, 18, and 24. Rectal temperatures were taken using a digital thermometer (GLA M-500; Agricultural electronics, San Luis Obispo, CA). All calves were monitored by trained personnel for clinical signs of BRDC and were based on criteria from the DART ${ }^{\mathrm{TM}}$ system (Pharmacia Upjohn Animal Health, Kalamazoo, MI) with some modifications as described [9]. Scores were assigned for each calf from 0 to 4 based where 1=mild clinical signs; $2=$ moderate clinical signs; $3=$ severe clinical signs; $4=$ moribund animals. 


\section{Total RNA isolation and cDNA synthesis}

Blood samples were collected at day -4 , day 0 (equivalent to 0 h), $12 \mathrm{~h}$ and $24 \mathrm{~h}$, and PBL were isolated and frozen at $-80^{\circ} \mathrm{C}$ in 1 $\mathrm{mL}$ of TRIzol reagent (Life Technologies, Carlsbad, CA) according to procedures described .Total mRNA was isolated according to manufacturer's recommendations, and the integrity of RNA was assessed by gel visualization of $18 \mathrm{~S}$ and $28 \mathrm{~S}$ ribosomal RNA. The purity and quantity of RNA was determined using a NanoDrop, ND 1000 Spectophometer (Thermo Fisher Scientific, Wilmington, DE, USA). After isolation, $2 \mu \mathrm{g}$ of mRNA was treated with DNase I Amplification Grade (Life Technologies) according to manufacturer's recommendation. Then cDNA was reversed transcribed from $2 \mu \mathrm{g}$ of RNA using $1 \mu \mathrm{L}$ of Superscript II Reverse Transcriptase (Life Technologies).

\section{Quantitative real time PCR}

Quantitative real time PCR (qRT-PCR) was used for analysis of three known interferon stimulated genes (ISG), MX dynamin- like GTPase 1 (MX1), ISG15 ubiquitin-like modifier, (ISG15) and receptor (chemosensory) transporter protein-4 (RTP4). Each cDNA sample was analyzed by qPCR utilizing primers and according to procedures reported. Glyceraldehyde-3-phosphate dehydrogenase (GAPDH), peptidylprolyl isomerase A(PPIA), and beta-actin were tested for stability using geNorm (Biogazell qbasePLUS2, Zwijnaarde, Belgium) and PPIA was selected.

\section{Statistical analysis}

Fold-change of ISG mRNA abundance in PBL was calculated using the $\Delta \Delta C T$ method [12]. Fold-change for each gene was the dependent variable and was tested against treatment, time, and treatment $x$ time using the MIXED procedure of SAS (Ver 9.2; SAS Institute). Significance level for all studies was set at $\mathrm{P}<0.10$. Steers served as the experimental units and was tested against time for clinical scores and temperature using the GLIMMIX procedure of SAS.

\section{Results}

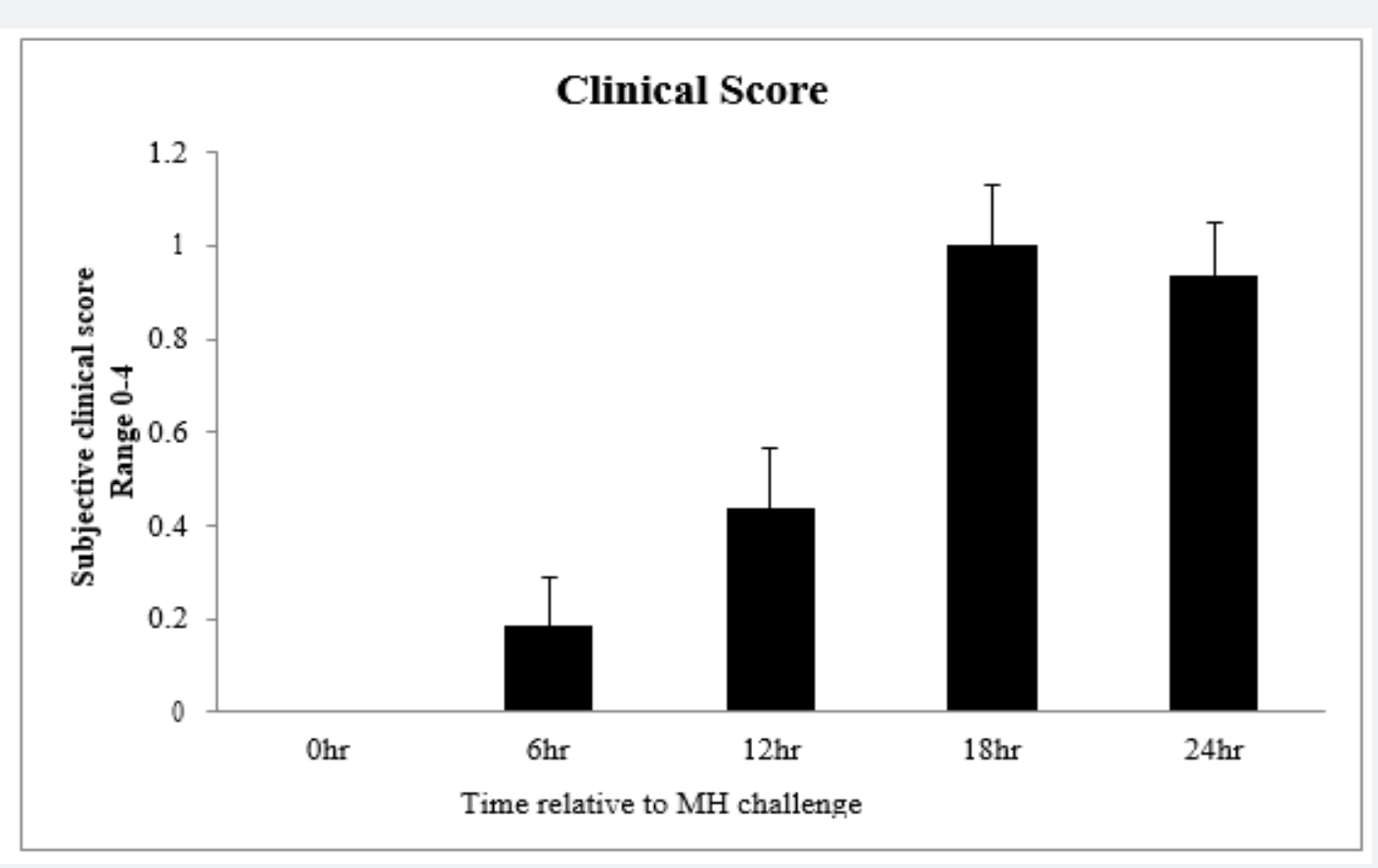

Figure 1: Clinical scores for the first $24 \mathrm{~h}$ after calves exposed to a bovine viral diarrhea virus type $1 \mathrm{~b}$ persistently infected calf on day -4 and subsequently challenged with Mannheimia haemolytica (MH) at $0 \mathrm{~h}$. Calves were monitored and scores recorded by trained personnel using the subjective criteria as follows: depression, abnormal appetite, and respiratory signs. Calves were given a score between 0 and 4 depending on the clinical signs and the severity of the signs. Time is in reference to the $\mathrm{MH}$ challenge at $0 \mathrm{~h}$. Scores increased after $0 \mathrm{~h}$ to peak at $18 \mathrm{~h}$ before decreasing to a score of 0 by day 7 . Scores were relatively low, but significant time effect was noted $(P<0.01)$. Mineral status was not significant $(P=0.87)$, allowing all animals to be pooled.

Clinical severity (CS) scores were documented for all animals and a significant time effect was noted $(\mathrm{P}<0.01)$ with scores peaking at about 1.1, $18 \mathrm{~h}$ after MH challenge (Figure.1). By $48 \mathrm{~h}$ after MH challenge, most calves returned to a CS of 0 , and by day 7 all CS were 0. Body temperatures rose after $\mathrm{MH}$ challenge to peak at just over $40^{\circ} \mathrm{C} 12 \mathrm{~h}$ after $\mathrm{MH}$ challenge and all calves returned to below $39.5^{\circ} \mathrm{C}$ by $24 \mathrm{~h}$ after challenge $(\mathrm{P}<0.01$; Figure. 2$)$. There was no effect of $\mathrm{Cu}$ deficiency on the production of ISG, nor was there a mineral by time effect, so data was pooled for all animals (P
$>0.10)$. There was a significant effect of time $(\mathrm{P}<0.05)$ for all ISG evaluated. At $0 \mathrm{~h}$, ISG15 levels increased 44 -fold compared to day -4 and remained elevated over 60 -fold for both $12 \mathrm{~h}$ and $24 \mathrm{~h}(\mathrm{P}$ $<0.01$; Figure 3). Receptor (chemosensory) transporter protein-4 increased $(\mathrm{P}<0.05)$ after BRD challenge and was 6-fold greater than day -4 samples at $12 \mathrm{~h}$ (Figure 4). Likewise, MX1 also increased $(\mathrm{P}<0.05)$ after BRD challenge with a 12-fold greater change than day -4 at $12 \mathrm{~h}$ (Figure 5). 


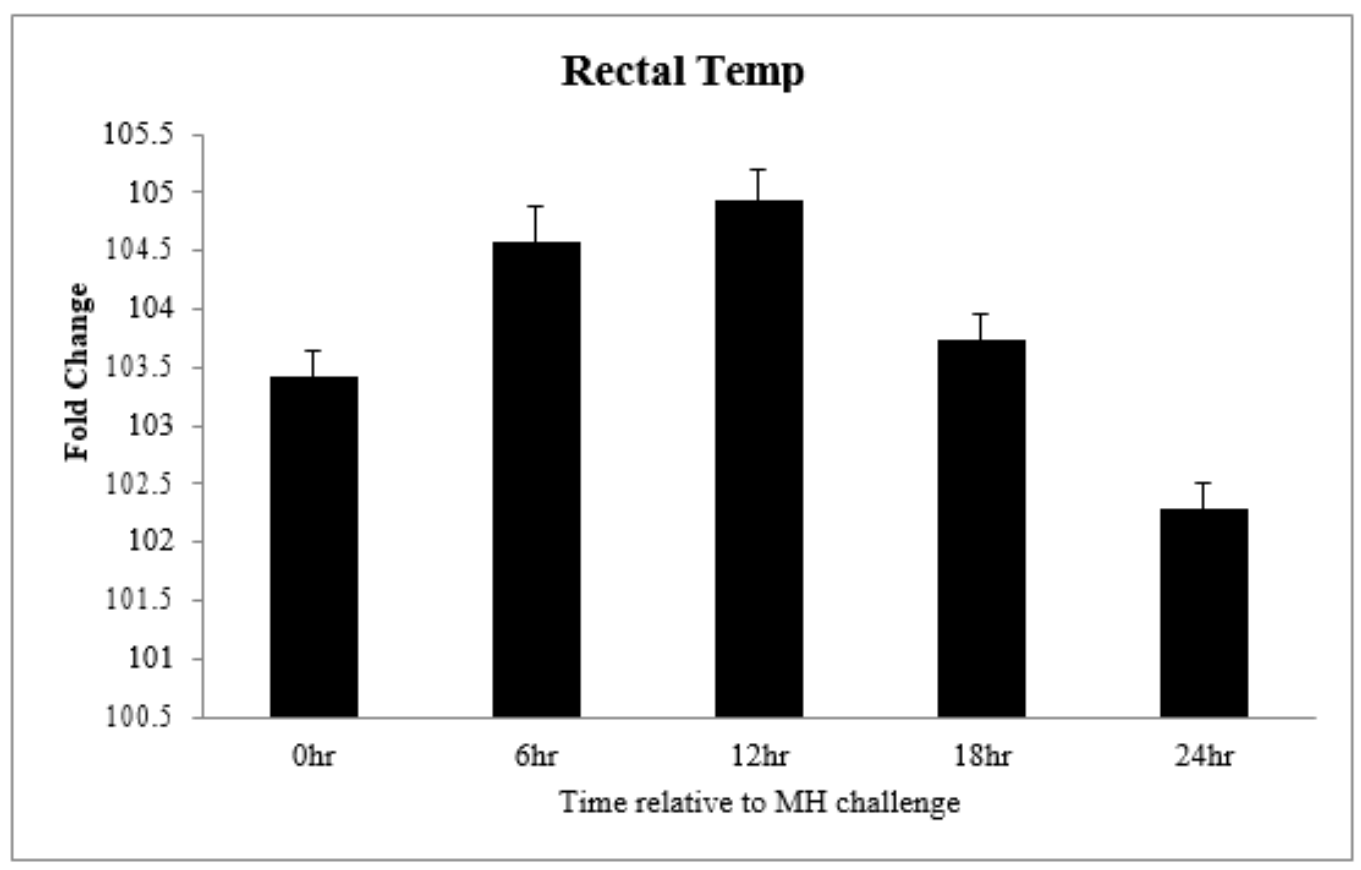

Figure 2: Rectal temperatures of the calves for the first $24 \mathrm{~h}$, following exposure to a calf persistently infected with bovine viral diarrhea virus type $1 \mathrm{~b}$ and subsequent Mannheimia haemolytica $(\mathrm{MH})$ challenge. Temperatures were taken by digital thermometer. Time is in reference to the $\mathrm{MH}$ challenge at $0 \mathrm{~h}$. There is an increase in temperature after the challenge, peaking at $12 \mathrm{~h}$ before decreasing to an average temp of $103.1 \circ \mathrm{F}$ at $24 \mathrm{~h}$. There was a significant time interaction $(P<0.01)$ but mineral status was not significant $(P=0.66)$.

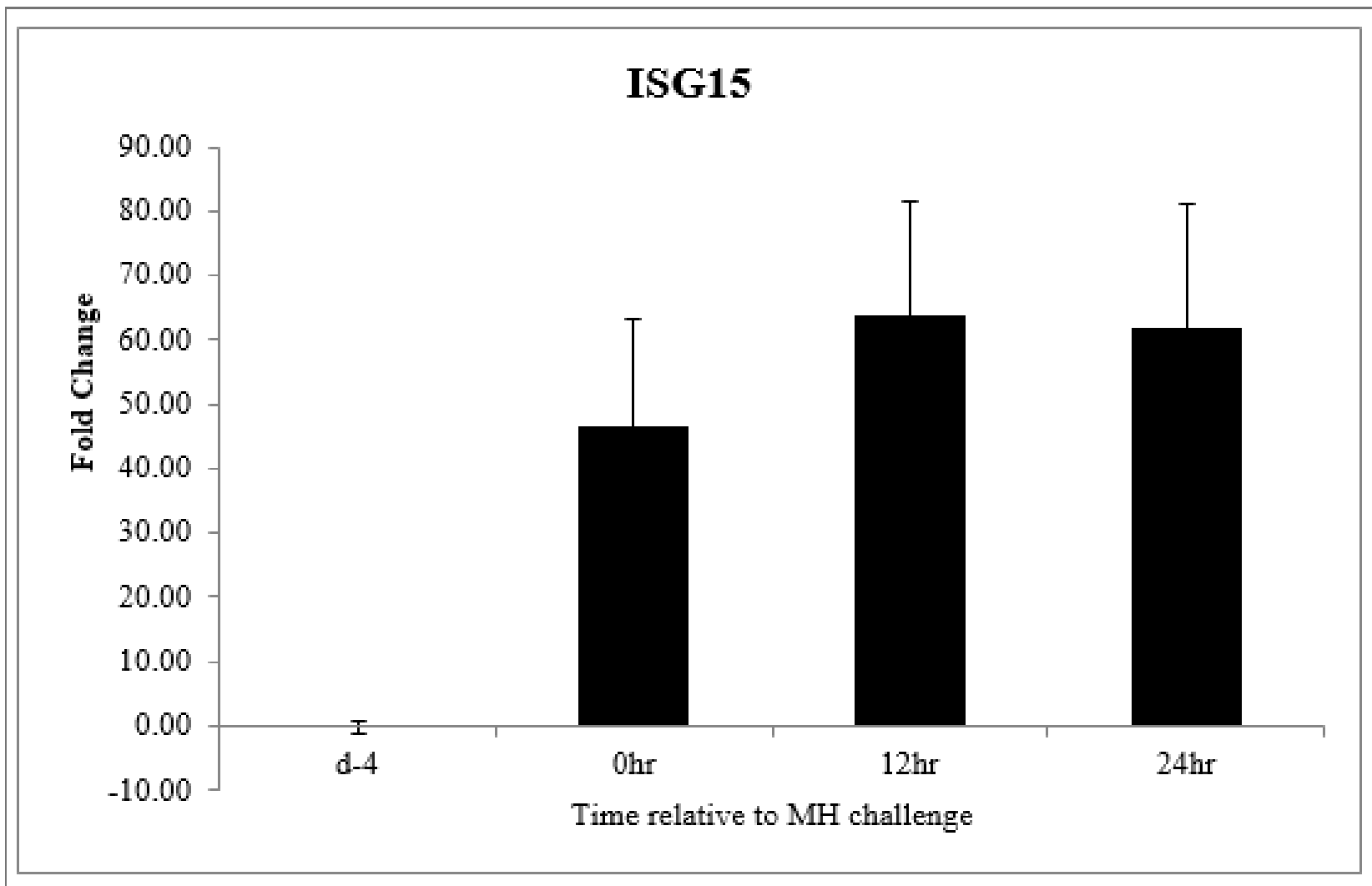

Figure 3: Interferon stimulated gene ISG15 ubiquitin-like modifier (ISG15), in response to calves exposed to a bovine viral diarrhea virus type $1 \mathrm{~b}$ persistently infected calf and subsequent Mannheimia haemolytica (MH) infection. There was no effect of treatment so mineral supplement and mineral deficient were pooled. ISG ubiquitin-like modifier fold changes are relative to the average of day -4 and were was calculated using the $\Delta \Delta \mathrm{Ct}$ method. Time is relative to the $\mathrm{MH}$ challenge at $0 \mathrm{~h}$. There was a marked increase in fold changes with maximum induction at $12 \mathrm{~h}$. Fold changes stayed above 60 -fold difference for $12 \mathrm{~h}$ and $24 \mathrm{~h}$. Time was a significant factor $(\mathrm{P}<0.05)$. 


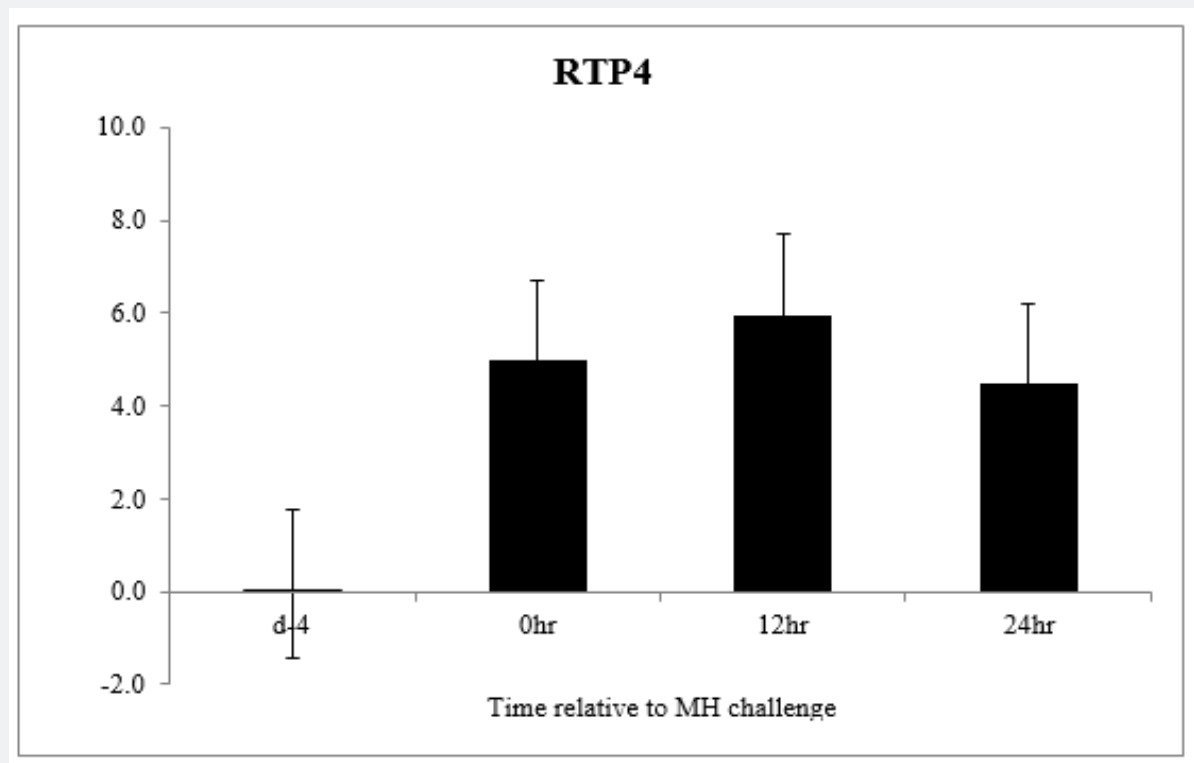

Figure 4: Interferon stimulated gene Receptor (chemosensory) transporter protein 4 (RTP4), in response to calves exposed to a bovine viral diarrhea virus type $1 \mathrm{~b}$ persistently infected calf and subsequent Mannheimia haemolytica $(\mathrm{MH})$ infection. There was no effect of treatment so mineral supplement and mineral deficient were pooled. RTP4 fold changes are relative to the average of day -4 and where was calculated using the $\Delta \Delta \mathrm{Ct}$ method. Time is relative to the $\mathrm{MH}$ challenge at $0 \mathrm{~h}$. The greatest fold increase was at $12 \mathrm{~h}$, with a 6 -fold greater change compared to day -4 , time was a significant factor at $(\mathrm{P}<0.05)$.

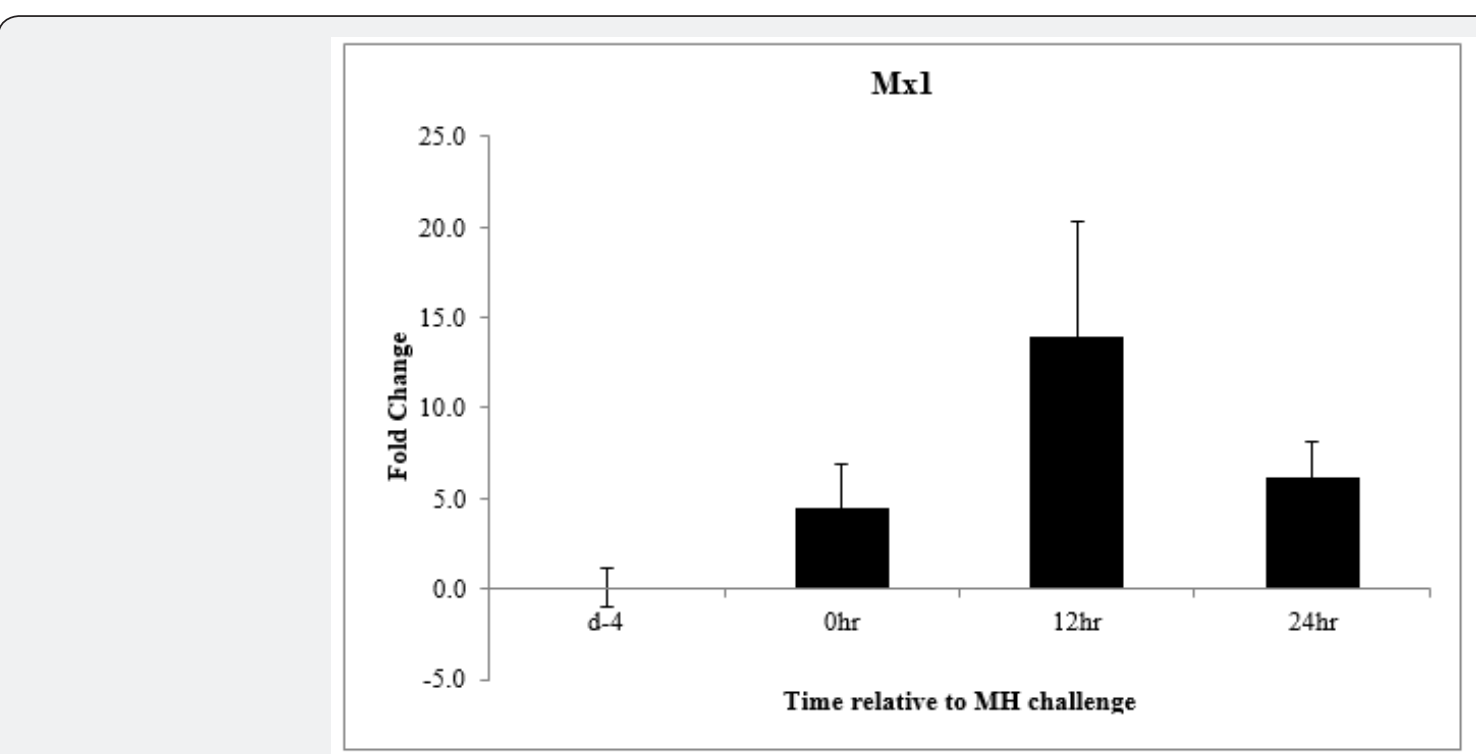

Figure 5: Interferon stimulated gene MX dynamin-like GTPase 1 (MX), in response to calves exposed to a bovine viral diarrhea virus type 1b persistently infected calf and subsequent Mannheimia haemolytica (MH) infection. There was no effect of treatment so mineral supplement and mineral deficient were pooled. MX1 fold changes are relative to the average of day -4 and where was calculated using the $\Delta \Delta \mathrm{Ct}$ method. Time is relative to the MH challenge at $0 \mathrm{~h}$. MX1 levels increased over 12-fold by $12 \mathrm{~h}$, causing a significant time effect to be observed $(P<$ 0.05).

\section{Discussion}

Animals entering a feedlot are subjected to a range of environmental stressors including movement, comingling with sick animals, dehydration, short-term loss of appetite, and diet changes. Dietary minerals can impact immune function in cattle and mineral deficiency could potentially predispose animals to illness. Ten days after challenge with infectious bovine rhinotracheitis virus, Serum antibody titers for infectious bovine rhinotracheitis virus were greater on d 10, and remained higher on d 14 and 17 in calves that were $\mathrm{Cu}$ deficient when compared to $\mathrm{Cu}$ adequate calves .Immunoglobulin $\mathrm{M}$ levels tended to be higher in $\mathrm{Cu}$ adequate calves than in $\mathrm{Cu}$ deficient calves and the $\mathrm{Cu}$ dependent enzyme, superoxide dismutase, activity was reduced in $\mathrm{Cu}$ deficient calves [13]. Serum immunoglobulin production, as well as Brucella abortus antibody titers, was reduced in $\mathrm{Cu}$ deficient calves challenged with Brucella abortus [14]. These studies suggest that $\mathrm{Cu}$ deficiency impedes the immune function of calves by delaying the antibody response, decreasing immunoglobulin levels, and decreasing $\mathrm{Cu}$ dependent enzymes for anti-inflammatory response.

Additionally, the number of B lymphocytes was markedly reduced, and monocytes were increased in $\mathrm{Cu}$ deficient calves, indicating that $\mathrm{Cu}$ status can impact immune cell populations. In 
calves that were $\mathrm{Cu}$ deficient a marked decrease in activity and phagocytosis of neutrophils was observed [15]. These studies indicate an impaired immune function in $\mathrm{Cu}$ deficient calves. However, in the current experiment $\mathrm{Cu}$ status had no effect on the IFN response in BVDV challenged calves. Bovine viral diarrhea virus is a single stranded RNA virus, member of the Pestivirus genus, family Flaviviridae [2]. Using a portion of the 5' untranslated region of BVDV isolates, by phylogenic analysis and PCR, BVDV was separated into BVDV1 with two sub genotypes, BVDV1a, BVDV1b and BVDV2 $[16,17]$. Calves can become infected with BDVD while still in utero. If the dam is infected between 30 and 120 days of gestation with BVDV, calves are considered persistently infected (PI) with BVDV. Persistently infected animals have lifelong infection and constantly shed the virus thereby maintaining and spreading the virus in the cattle population. If calves are infected after 120 days of gestation, they are considered transiently infected (TI) and can produce an immune response [18-21]. Interferons are among the first cytokines released in response to viral pathogens and function to combat viral infections by viral growth-inhibitory properties [5]. It is thought that BVDV evades the host immune response by interrupting the type I interferon pathway. Non cytopathic-BVDV targets IRF-3, preventing it from binding to DNA, which in turn blocks the induction of IFN- $\beta$ [23]. The amino terminus protease (NPro) of the BVDV genome targets IRF-3 for polyubiquitination and proteasomal degradation [8] thus preventing release of IFN $\alpha$ and IFN $\beta$. However, in vivo work suggested that the type I IFN production is maintained after BVDV infection. Work by Henningson and others (2009) evaluated the type I IFN pathway in calves challenged with either an NPro intact BVDV or an NPro deleted BVDV. Interestingly, it was observed that the NPro deleted BVDV caused an earlier up regulation of interferon concentrations than the NPro intact BVDV, with increased IFN concentrations day 3 to 4 and day 5 after virus challenge, respectively [22].

In the current study, ISG increase as early as 4 days after comingling with a PI calf which also indicates that the type I IFN pathway is recruited early after BVDV exposure. Calves that are transiently or persistently infected with BVDV2, also exhibit an increase in expression of IFN $\alpha / \beta$ after viral exposure $[23,24]$. Interferon stimulated genes, ISG15, 2'5' oligoadenylate synthetase-1 (OAS-1), ds RNA dependent protein kinase (PKR), and MX dynaminlike GTPase 2 (MX2) levels increased in PI and TI cattle fetuses, as well as a PI steers infected with BVDV2 [25].

Due to the variability of the genetics and virulence of BVDV strains, it has been suggested that the differences in strains could cause a difference in immunosuppression, and subsequent effects on the type I IFN pathway. Calves that were inoculated by intranasal aerosolization with a low virulence type 1a non-cytopathic BVDV or a high virulence type 2 non-cytopathic BVDV showed increased MX1, ISG15, OAS-1, and PKR in the spleen and trachea-bronchial lymph nodes indicating that the strain of BVDV does not change the effect on the type I IFN pathway [26]. In the U.S. feedlot industry, initial exposure to BVDV primarily comes from contact with PI animals. The current study attempted to mimic conditions of natural exposure found in shipment of cattle to the feedlot. Similar to other in vivo studies, a pronounced type I IFN response was observed with increased levels of ISG within 4 days after BVDV exposure [27-30].Of particular interest, is the up regulation of ISG at or before $\mathrm{d}$ 0, MH challenge, suggesting that BVDV alone elicits a type I IFN response [31,32].

\section{Conclusion}

Though several studies have implicated mineral supplementation with immune function, mineral status did not appear to affect type I IFN signaling. Consistent with other in vivo work, calves exposed to a calf that was persistently infected with BVDV exhibited a rapid and robust type I IFN response. The observation of increased type I IFN activity is in contradiction to in vitro work which suggests BVDV impairs the type I IFN response. However, animals in the current experiment had relatively low clinical scores and it been possible that more severe cases of BRDC which involve BVDV could impair the type I IFN response.

\section{Acknowledgement}

None.

\section{Conflict of Interest}

Authors declare no conflict of interest.

\section{References}

1. Chirase NK, Green LW (2000) Influence of oral natural interferon- $\alpha$ on performance and rectal temperature of newly received beef steers. Proceedings of the Annual Meeting of the Western Section of American Society of Animal Science, Davis, California 51: 411-414.

2. Meyers G, Thiel HJ (1996) Molecular characterization of pestiviruses. Advances in Virus Research 47:53-118.

3. Ellis JA (2001) The immunology of the bovine respiratory disease complex. Vet Clin North Am Food Anim Pract 17(3): 535-549.

4. Burciaga Robles LO, Step DL, Krehbiel CR, Holland BP, Richards CJ, et al. (2010) Effects of exposure to calves persistently infected with bovine viral diarrhea virus type $1 \mathrm{~b}$ and subsequent infection with mannheimia haemolytica on clinical signs and immune variables: model for bovine respiratory disease via viral and bacterial interaction. J Anim Sci 88(6): 2166-2178.

5. Platanias LC (2005) Mechanisms of type I and type II interferon medicated signaling. Nat Rev Immunol 5(5): 375-386.

6. McNab F, Mayer Barber K, Sher A, Wack A, O Garra A (2015) Type I interferons in infectious disease. Nat Rev Immunol 15(2): 87-103.

7. Baigent SJ, Zhang G, Fray MD, Flick-Smith H, Goodbourn S, et al. (2002) Inhibition of beta interferon transcription by noncytopathogenic bovine viral diarrhea virus is through an interferon regulatory fact 3-dependent mechanism. J Virol 76(18): 8979-8988.

8. Hilton L, Moganeradj K, Zhang G, Chen YH, Randall RE, et al. (2006). The npro product of bovine viral diarrhea virus inhibits DNA binding by interferon regulatory factor 3 and targets it for proteasomal degradation. J Virol 80(23): 1117-1123.

9. Stanton TL, Schutz D, Swenson C (2001) Trace mineral supplementation in the presence of antagonists on growth performance, health, and carcass characteristics of transport-stressed calves. The Professional Animal Scientist, 17(2): 101-108.

10. Kegley EB, Pass MR, Moore JC, Larson CK (2012) Supplemental trace minerals (zinc,copper, manganese, and cobalt) as Availa-4 or inorganic sources for shipping-stressedbeef cattle. The Professional Animal Scientist 28(3): 313-318. 
11. Burciaga Robles LO, Step DL, Krehbiel CR, Holland BP, Richards CJ, et al. (2010) Effects of exposure to calves persistently infected with bovine viral diarrhea virus type $1 \mathrm{~b}$ and subsequent infection with mannheimia haemolytica on clinical signs and immune variables: model for bovine respiratory disease via viral and bacterial interaction. J Anim Sci 88(6): 2166-2178.

12. M, Andrade JM, Bengtsson M, Forootan A, Jonak J, et al. (2006) The realtime polymerase chain reaction. Mol Aspects Med 27(2): 95-125.

13. Stabel JR, Spears JW, Brown TT (1993) Effect of copper deficiency on tissue, blood characterisics, and immune function of calves challenged with infectious bovine rhinotracheitisvirus and Pasteurella hemolytica. J Anim Sci 71(5): 1247-1255.

14. Cerone S, Sansiananea A, Auza N (1995) Copper deficiency alters the immune response of bovine. Nutrition Research 15(9): 1333-1341.

15. Cerone SI, Sansianea AS, Streitenberger SA, Garcia MC, Auza NJ (1998) The effect of copper deficiency on the peripheral blood cells of cattle. Vet Res Commun 22(1): 47-57.

16. Ridpath JF, Bolin SR, Dubovi EJ (1994) Segregation of bovine viral diarrhea virus into genotypes. Virology 205(1): 66-74.

17. Ridpath JF, Bolin SR (1998) Differentiation of types 1a, $1 \mathrm{~b}$ and 2 bovine viral diarrhea virus (BVDV) by PCR. Mol Cell Probes. 12(2): 101-106.

18. Bognar K (1972) Foetal active immunization of calves following inoculation of the dam with bovine viral diarrhea vaccine. Acta Vet Acad Sci Hung 23(1): 1-11.

19. Kahrs RF (1973) Effects of bovine viral diarrhea on the developing fetus. American Veterinary Medical Association, 163: 877-878.

20. McClurkin AW, Littledike ET, Cutlip RC, Frank GH, Coria MF, et al. (1984) Production of cattle immunotolerant to bovine viral diarrhea virus. Can J Comp Med 48(2): 156-161.

21. Stokstad M, Loken T (2002) Pestivirus in Cattle: Experimentally Induced Persistent Infection in Calves. J Vet Med Series B 49(10): 494-501.

22. Henningson JN, Topliff CL, Gil LHV, O’Donis R, Steffen DJ, et al. (2009) Effect of the viral protein Npro on virulence of bovine viral diarrhea virus and induction of interferon type I in calves. Am J Vet Res 70(9): $1117-1123$.
23. Charleston B, Brackenbury L, Carr B, Fray M, Hope J, et al. (2002) Alpha/ beta and gamma interferons are induced by infection with noncytopathic bovine viral diarrhea virus in vivo. J Virol 76(2): 923-927.

24. Brackenbury LS, Carr BV, Stamataki Z, Prentice H, Lefevre EA, et al. (2005) Identification of a cell population that produces alpha/beta interferon in vitro and in vivo in response to noncytopathic bovine viral diarrhea virus. J Virol 79(12): 7738-7744.

25. Shoemaker ML, Smirnova NP, Bielefeldt Ohmann H, Austin KJ, Van Olphen A, et al (2009) Differential expression of the type I interferon pathway during persistent and transient bovine viral diarrhea virus infection. J Interferon Cytokine Res 29(1): 23-35.

26. Palomares RA, Walz HG, Brock KV (2013) Expression of type I interferoninduced antiviral state and pro-apoptosis markers during experimental infection with low or high virulence bovine viral diarrhea virus in beef calves. Virus Res 173(2): 260-269.

27. George MH, Nockels CF, Stanton TL, Johnson B, Cole NA, et al. (1997) Effect of source and amount of zinc, copper, manganese, and cobalt fed to stressed heifers on feedlot performance and immune function. The Professional Animal Scientist 13(2): 84-89.

28. Gifford CA, Assiri AM, Satterfield MC, Spencer TE, Ott TL, 2008. Receptor transporter protein 4 (RTP4) in endometrium, ovary, and peripheral blood leukocytes of pregnant and cyclic ewes. Biol Reprod 79(3): 518524.

29. Medzhitov R, Janeway CA (1997) Innate immunity: impact on the adaptive immune response. Curr Opin Immunol 9(1): 4-9.

30. NAHMS (2011) Types and costs of respiratory diseases treatment in U.S. feedlots. USDA.APHIS, National Animal Health Monitoring system: 1015.

31. Randall RE, Goodbourn S (2008) Interferon and viruses: an interplay between induction, signaling, antiviral responses and virus countermeasures. J Gen Virol 89(1): 1-47.

32. Step DL, Krehbiel CR, Depra HA, Cranston JJ, Fulton RW, et al. (2008) Effects of commingling beef calves from different sources and weaning protocols during a forty-two-dayreceiving period on performance and bovine respiratory disease. J Anim Sci 86(11): 3146-3158. 